\title{
RANCANG BANGUN ROBOT VACUUM CLEANER DENGAN MENERAPKAN PROPOSITIONAL LOGIC UNTUK PENGATURAN NAVIGASI
}

\author{
Zamroni Adeyanto ${ }^{1}$, Ahmad Izzuddin ${ }^{2}$, Nuzul Hikmah ${ }^{3}$ \\ 1,2,3 Program Studi Teknik Elektro, Universitas Panca Marga Probolinggo \\ zamroniade08@gmail.com
}

\begin{abstract}
ABSTRAK
Dalam kehidupan sehari-hari sering kita jumpai kotoran ataupun debu yang tersebar di dalam maupun di luar rumah, ini disebabkan karena adanya partikel debu yang datang melalui udara dan menempel pada setiap permukaan rumah. Membersihkan lantai dari kotoran ataupun debu adalah suatu kegiatan yang harus dilakukan oleh masyarakat agar dapat menjaga kebersihan rumah sehingga rumah akan tampak bersih dan indah. Untuk membersihkan debu yang selalu menempel pada lantai biasanya masyarakat menggunakan alat sederhana berupa sapu ijuk ataupun kemoceng serta adapula yang menggunakan vacuum cleaner manual yang masih dikontrol oleh manusia Hal ini dinilai sangat konvensional karena dengan menggunakan alat tersebut pekerjaan akan memakan energi dan waktu yang lama dibandingkan dengan menggunakan robot vacuum cleaner yang bernavigasi secara otomatis. Berdasarkan permasalahan yang telah diuraikan peneliti akan merancang dan membangun sebuah robot vacuum cleaner yang dapat bernavigasi secara otomatis dan menerapkan logika propositional logic pada robot sehingga robot dapat kembali ke jalur setelah melewati rintangan agar tidak terdapat daerah yang tidak dilewati oleh robot vacuum cleaner tersebut. Dari penelitian ini berhasil membangun robot dengan menerapkan propositional logic yang berintegrasi dengan sistem kontrol PID, yang mana robot dapat mengitari seluruh ruangan dengan skala $160 \mathrm{~cm}^{2}$ dan dapat menghindari rintangan lalu kembali pada jalur yang belum dilalui oleh robot. Pada penelitian ini dilakukan 10 kali pengujian pada robot dalam bernavigasi sehingga didapat presentase keberhasilan robot dalam bernavigasi yaitu berhasil $90 \%$.
\end{abstract}

Kata Kunci : Arduino, Robot, Vacuum Cleaner, Propositional Logic.

\section{PENDAHULUAN}

Permasalahan yang sering kita jumpai saat berada di lingkungan rumah ialah banyaknya debu maupun kotoran yang bertebaran baik itu melalui udara ataupun menempel di permukaan rumah yang dapat dibersihkan dengan berbagai cara baik secara manual maupun secara otomatis.Banyak peneliti yang merancang dan membangun robot vacuum cleaner otomatis dengan berbagai macam metode yang dikembangkan, diantaranya : Rancang bangun prototype robot avoider penyedot debu otomatis berbasis Arduino (Prasetyo, 2016), Implementasi Metoe Maze dan Pid pada robot Vacuum Cleaner Automatic (Tresnawan, 2015), Implementasi Behavior Based Control Dan PID Pada Robot vacuum Cleaner (Trianes, 2015).

Dari penelitian yang telah dipaparkan sebelumnya beberapa peneliti menggunakan metode Proportional Integral Derivative (PID) yang berfunmgsi untuk menstabilkan rotation per minute (RPM) pada pergerakan kedua roda robot yang dikontrol oleh mikrokontroler Arduino Uno. Sehingga ketika robot melewati lintasan yang akan dilalui, pergerakan yang dihasilkan menjadi stabil dan mengurangi terjadinya perbelokan pada saat robot berjalan lurus.

Dalam penggunaan metode yang sudah dilakukan dalam penelitian sebelumnya terdapat kekurangan dalam pergerakan robot vacuum cleaner yaitu hanya dapat membersihkan kotoran atau debu pada suatu lintasan yang tidak terdapat rintangan berupa kursi, meja ataupun benda yang menghalangi pekerjaan robot tersebut, sehingga ketika robot yang bernavigasi secara otomatis ini mendapati sebuah rintangan maka robot ini tidak dapat kembali ke jalur yang tidak terlewati setelah melewati rintangan kecil seperti kaki meja. Oleh karena itu peneliti akan menggunakan logika yang dianggap tepat untuk menyelesaikan permasalahan tersebut, peneliti akan menggunakan Propositional logic untuk memecahkan permasalahan tersebut dimana logika ini adalah suatu pernyataan mengenai hal-hal yang dapat dinilai dengan benar atau salah (true or false) yang dapat menerima informasi dari lingkungan dan merepresentasikannya dalam bentuk proporsisi sehingga robot dapat menghindari rintangan dan dapat kembali pada jalur yang belum dilalui.

\section{LANDASAN TEORI}

\subsection{Arduino $U N O$}

Arduino adalah sebuah platform elektronik yang bersifat open source serta mudah digunakan, hal tersebut ditujukan bahwa siapapun dapat mmbuat proyek interaktif dengan mudah dan menarik (Mochamad dkk., 2017).

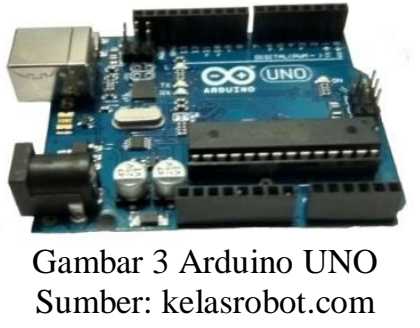

Copyright (c) 2020 Jurnal Mnemonic 


\subsection{Sensor Ultrasonik HC-SR04}

Sensor ultrasonik adalah sensor yang dapat mengukur jarak dengan rentan mulai $2 \mathrm{~cm}$ sampai $4 \mathrm{~cm}$ dengan akurasi mencapai $3 \mathrm{~mm}$. Dimana pada sensor ini terdapat transmitter, receiver dan control circuit.

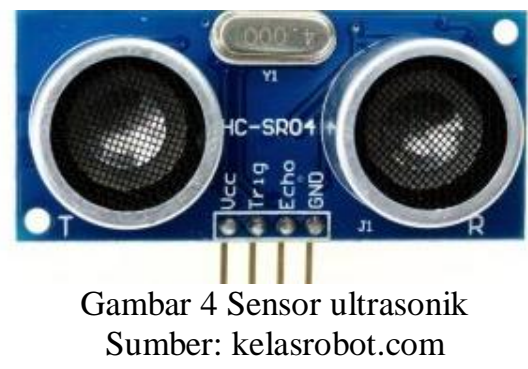

\subsection{Motor Servo}

Motor servo adalah sebuah motor DC yang dilengkapi rangkaian kendali dengan sistem closed feedback yang terintegrasi dalam motor tersebut, motor servo disusun dari sebuah motor DC, gearbox, variabel resistor (VR) atau potensio meter dan rangkaian kontrol. Motor servo dapat berputar dua arah ( $C W$ dan $C C W$ ), arah dan sudut pergerakan rotor dari motor servo dapat dikendalikan dengan memberikan lebar pulsa (duty cycle) sinyal PWM pada bagian pin kontrolnya (Safullah, 2015).

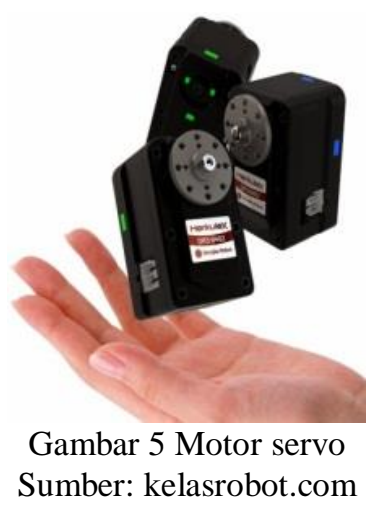

\subsection{Sensor Kompas HMC5883L}

Sensor kompas HMC5883L merupakan Magnetic Compass yang menggunakan sensor medan magnet untuk mendeteksi medan magnet bumi. Sensor kompas ini memerlukan tegangan sebesar 3.3V (DC) dan konsumsi arus sebesar $15 \mu \mathrm{A}$, arah mata angin pada $H M C 5883 L$ dibagi dalam bentuk derajat sebagai berikut : Utara $\left(0^{\circ} 360^{\circ}\right)$, Timur $\left(90^{\circ}\right)$, Selatan $\left(180^{\circ}\right)$, Barat $\left(270^{\circ}\right)$.

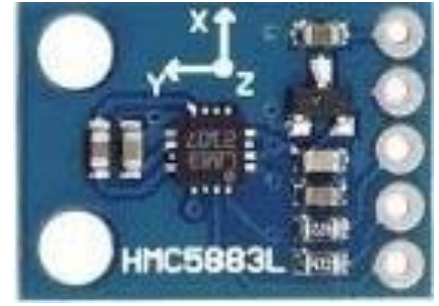

Gambar 6 Sensor Kompas

Sumber: kelasrobot.com

\section{METODE}

\subsection{Diagram Alir}

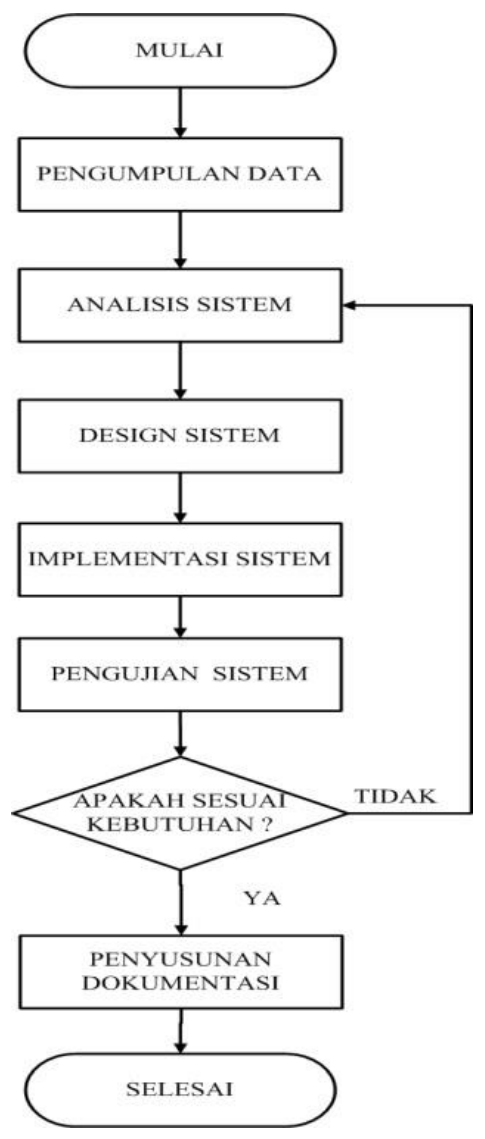

Gambar 1 Diagram Alir Penelitian

\subsection{Design Sistem Hardware}

Desain sistem merupakan tahapan sebelum membuat suatu sistem dan merupakan merupakan rancangan perangkat keras yang akan digunakan untuk membangun suatu sistem. Berikut ini adalah desain sistem yang digambarkan dalam bentuk diagram blok. 


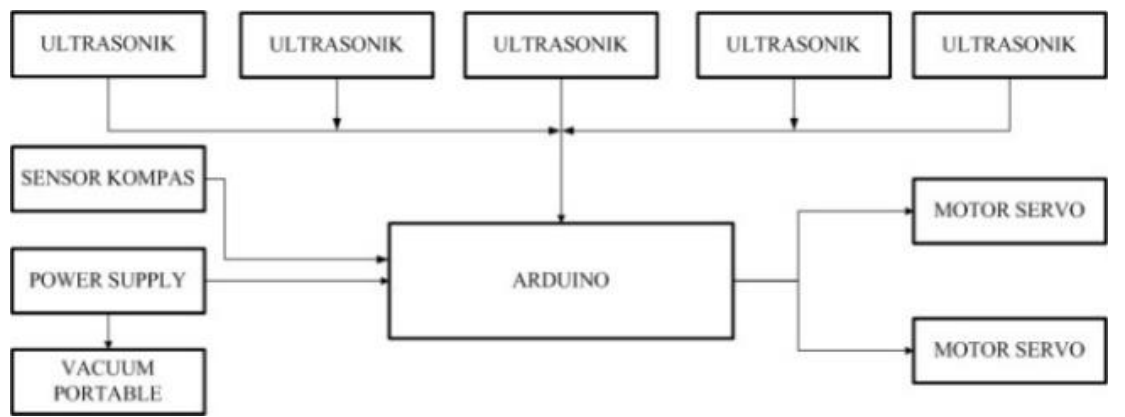

Gambar 2 Diagram blok design hardware

\subsection{Design Sistem Software}

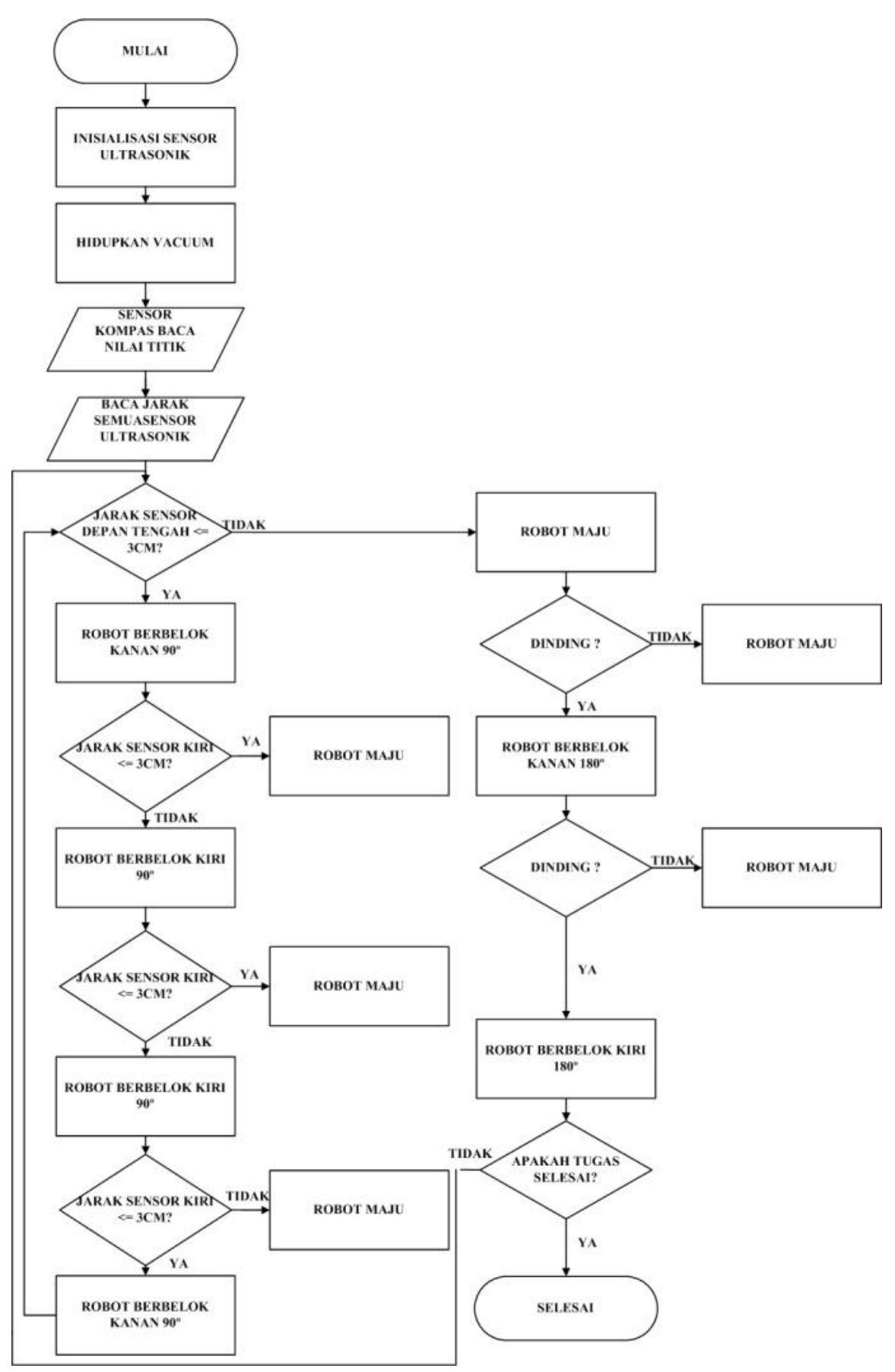

Gambar 7 Design Sistem Software 


\section{PEMBAHASAN}

Pada bagian ini menjelaskan konfigurasi dari masing-masing komponen yang digunakan sehingga membentuk sebuah sistem yang dapat berjalan sesuai kebutuhan supaya siap dioperasikan. Pada bagian ini juga dilakukan pengujian terhadap perangkat keras setelah dilakukan implementasi sistem, setelah pengujian dilakukan maka akan terdapat kekurangan dan kelebihan untuk pengembangan sistem selanjutnya. Berikut ini adalah implementasi perangkat keras yang telah di uraikan sebelumnya.

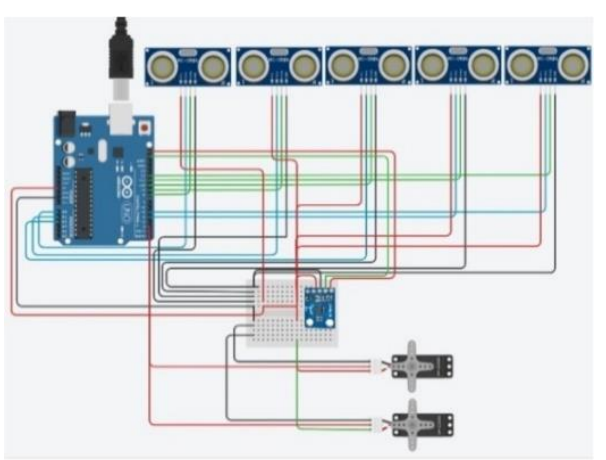

Gambar 8 Skema Perangkat Keras Sumber: Dokumen pribadi

Pada gambar 8 merupakan skema rangkaian dari sistem robot vacuum cleaner yang dibangun, untuk mengimplementasikan skema rangkaian tersebut diperlukan ketelitian pemasangan kabel baik pada pin mikrokontroller atapun pada pin dari komponen yang digunakan.

Selanjutnya peneliti melakukan design chasis robot atau body robot yang akan digunakan untuk penempatan komponen-komponen robot yang dipakai seperti mikrokontroler arduino, sensor dan actuator robot. Dalam tahap ini yang perlu diperhatikan adalah mekanisme dari komponenkomponen yang dunakan supaya robot berjalan dengan baik. Berikut ini adalah desain dari chasis robot yang akan dibangun

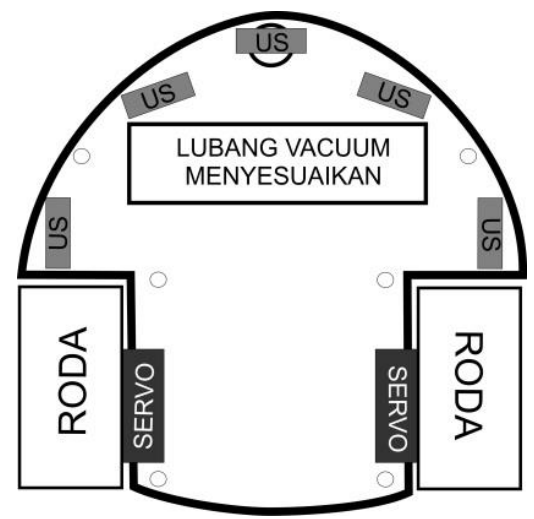

Gambar 9 Design chasis robot Sumber: Dokumen pribadi
Tahapan selanjutnya yaitu implementasi rangkaian robot yang mengacu pada skema rangakaian robot. Setelah implementasi dilakukan untuk membangun sebuah robot peneliti melakukan dokumentasi hasil dari robot yang sudah dibangun.
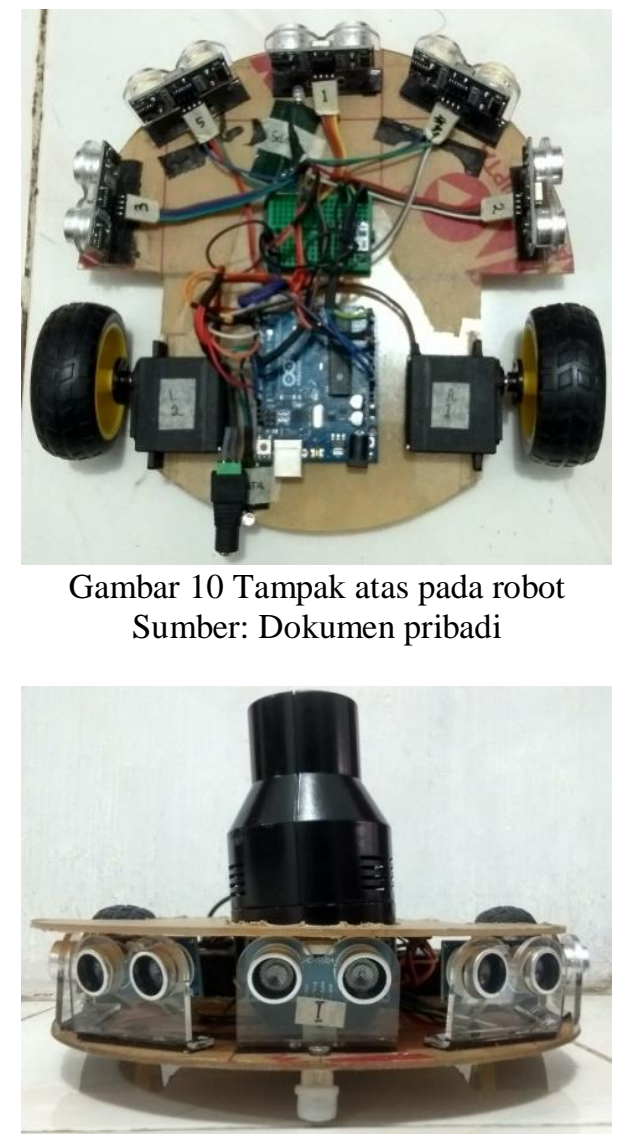

Gambar 11 Robot dengan vacuum cleaner Sumber: Dokumen pribadi

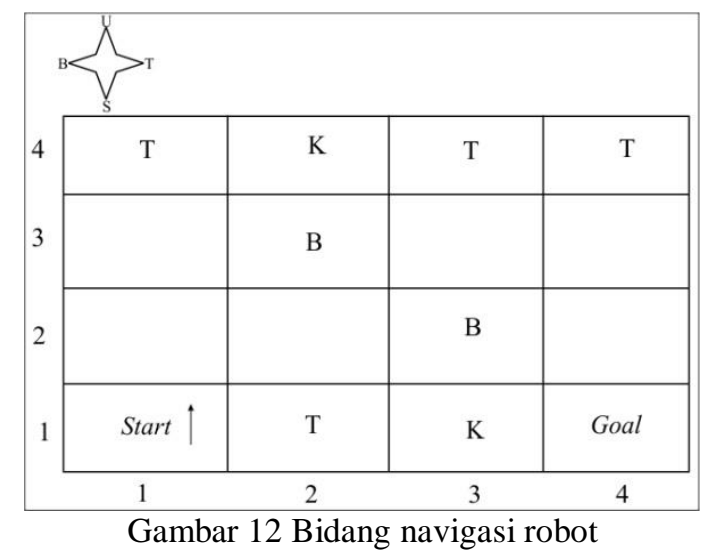

Keterangan:

$\begin{array}{ll}\text { Start } & \text { : Posisi awal robot } \\ \mathrm{T} & \text { : Dinding } \\ \mathrm{K} & : \text { Kardus } \\ \mathrm{B} & : \text { Botol } \\ \text { Goal } & : \text { Finish atau Tujuan akhir robot }\end{array}$


Pengujian sensor kompas pada sistem navigasi propositional logic yang telah di implementasikan pada robot.

Pengujian menghadap utara $(x>600 \& x<$ $1250 \& \mathrm{y}<0)$

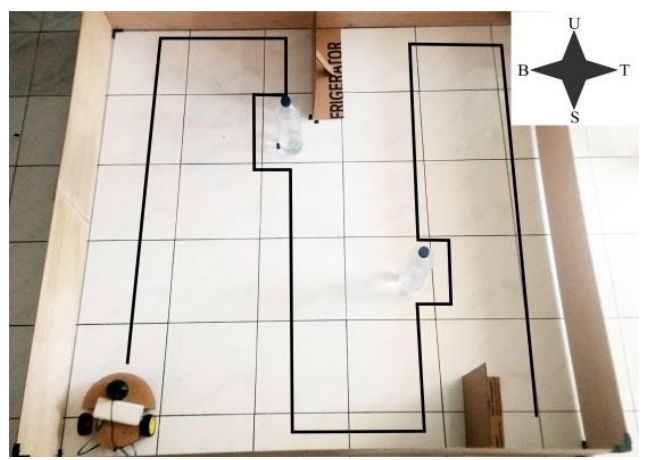

Gambar 13 Pengujian menghadap utara

Sumber: Dokumen pribadi

Tabel 1. Pengujian Navigasi Robot

\begin{tabular}{|c|c|c|}
\hline $\begin{array}{c}\text { Pengujian } \\
\text { Ke- }\end{array}$ & Hasil Pengujian & Keterangan \\
\hline 1 & $\begin{array}{l}\text { Pada saat start } \\
\text { robot bernavigasi } \\
\text { dengan baik dan } \\
\text { mengitari seluruh } \\
\text { ruangan uji, akan } \\
\text { tetapi pada posisi } \\
(4,4) \text { robot } \\
\text { menabrak dinding. }\end{array}$ & Gagal \\
\hline 2 & $\begin{array}{l}\text { Pada saat start } \\
\text { robot bernavigasi } \\
\text { dengan baik dan } \\
\text { mengitari seluruh } \\
\text { ruangan uji dan } \\
\text { berhenti pada posisi } \\
\text { goal }(4,1)\end{array}$ & Berhasil \\
\hline 3 & $\begin{array}{l}\text { Pada saat start } \\
\text { robot bernavigasi } \\
\text { dengan baik dan } \\
\text { mengitari seluruh } \\
\text { ruangan uji dan } \\
\text { berhenti pada posisi } \\
\text { goal }(4,1)\end{array}$ & Berhasil \\
\hline 4 & $\begin{array}{l}\text { Pada saat start } \\
\text { robot bernavigasi } \\
\text { dengan baik dan } \\
\text { mengitari seluruh } \\
\text { ruangan uji dan } \\
\text { berhenti pada posisi } \\
\text { goal }(4,1)\end{array}$ & Berhasil \\
\hline 5 & $\begin{array}{l}\text { Pada saat start } \\
\text { robot bernavigasi } \\
\text { dengan baik dan } \\
\text { mengitari seluruh } \\
\text { ruangan uji dan } \\
\text { berhenti pada posisi } \\
\text { goal }(4,1)\end{array}$ & Berhasil \\
\hline
\end{tabular}

\begin{tabular}{|c|c|c|}
\hline 6 & $\begin{array}{l}\text { Pada saat start } \\
\text { robot bernavigasi } \\
\text { dengan baik dan } \\
\text { mengitari seluruh } \\
\text { ruangan uji dan } \\
\text { berhenti pada posisi } \\
\text { goal }(4,1)\end{array}$ & Berhasil \\
\hline 7 & $\begin{array}{l}\text { Pada saat start } \\
\text { robot bernavigasi } \\
\text { dengan baik dan } \\
\text { mengitari seluruh } \\
\text { ruangan uji dan } \\
\text { berhenti pada posisi } \\
\text { goal }(4,1)\end{array}$ & Berhasil \\
\hline 8 & $\begin{array}{l}\text { Pada saat start } \\
\text { robot bernavigasi } \\
\text { dengan baik dan } \\
\text { mengitari seluruh } \\
\text { ruangan uji dan } \\
\text { berhenti pada posisi } \\
\text { goal }(4,1)\end{array}$ & Berhasil \\
\hline 9 & $\begin{array}{l}\text { Pada saat start } \\
\text { robot bernavigasi } \\
\text { dengan baik dan } \\
\text { mengitari seluruh } \\
\text { ruangan uji dan } \\
\text { berhenti pada posisi } \\
\text { goal }(4,1)\end{array}$ & Berhasil \\
\hline 10 & $\begin{array}{l}\text { Pada saat start } \\
\text { robot bernavigasi } \\
\text { dengan baik dan } \\
\text { mengitari seluruh } \\
\text { ruangan uji dan } \\
\text { berhenti pada posisi } \\
\text { goal }(4,1)\end{array}$ & Berhasil \\
\hline
\end{tabular}

Pada tabel pengujian tersebut didapatkan kesimpulan bahwa tingkat keberhasilan robot dalam bernavigasi ialah $90 \%$ dengan perhitungan sebagai berikut.

Presentase $=$ Jumlah Pengujian Berhasil x 100\%

$$
\begin{array}{r}
=\frac{9}{10} \times 100 \% \\
=90 \%
\end{array}
$$$$
\text { Jumlah Pengujian }
$$

\section{KESIMPULAN}

Penerapan logika propositional logic berhasil membuat robot mengetahui lingkungan dalam bernavigasi dimana robot dapat mengetahui dinding maupun rintangan sehingga dapat mengambil keputusan untuk menghindar dari rintangan dan Robot vacuum cleaner juga dapat mengetahui arah dari penerapan sensor kompas HMC55883L berdasarkan nilai yang diperoleh dan penetapan nilai dari arah mata angin yang spesifik. 


\section{DAFTAR PUSTAKA}

[1] Fajar, Mochamad dan Hidayat.2017. Mudah Belajar Mikrokontroler "Arduino". Bandung: Informatika Bandung

[2] Joni, Koko. 2016. Robot Line Follower Berbasis Proportional Integral Dervative (PID) Untuk Lintasan Dengan Sudut Ekstrim. Program Studi Teknik Elektro, Fakultas Teknik, Universitas Trunojoyo Madura. Vol.8, No.2

[3] Kadir, Abdul.2018. Dasar Pemrograman Robot Menggunakan “Arduino”. Yogyakarta: Andi

[4] Suyanto.2014. Artificial Intelligence "Searching, Reasoning, Planning dan
Learning”. Yogyakarta: Informatika Bandung

[5] Saefullah, Asep. 2015. Sistem Kontrol Robot Pemindah Barang Menggunakan Aplikasi Android Berbasis Arduino UNO. Vol.8, No.2

[6] Trianes, Agustian. 2015. Implementasi Behavior Based Control dan PID Pada Robot Vacuum Cleaner. Program Studi Teknik Elektro, Fakultas Teknik, Universitas Internasional Batam. Vol.1, No.2

[7] Tresnawan, Dian. 2015. Implementasi Metode Maze dan PID Pada Robot Vacuun Cleaner Automatic. Program Studi Teknik Elektro, Fakultas Teknik, Universitas Internasional Batam. Vol.1, No.4 